\title{
RÜDIGER, Jan, Aristokraten und Poeten. Die Grammatik einer Mentalität im tolosanischen Hochmittelalter
}

\section{Stéphane Péquignot}

\section{OpenEdition}

\section{Journals}

Édition électronique

URL : http://journals.openedition.org/ifha/1175

DOI : 10.4000/ifha.1175

ISSN : 2198-8943

Éditeur

IFRA - Institut franco-allemand (sciences historiques et sociales)

Référence électronique

Stéphane Péquignot, «RÜDIGER, Jan, Aristokraten und Poeten. Die Grammatik einer Mentalität im tolosanischen Hochmittelalter », Revue de l'IFHA [En ligne], Date de recension, mis en ligne le 01 janvier 2002, consulté le 22 septembre 2020. URL : http://journals.openedition.org/ifha/1175 ; DOI : https:// doi.org/10.4000/ifha. 1175

Ce document a été généré automatiquement le 22 septembre 2020.

(C)IFHA 


\title{
RÜDIGER, Jan, Aristokraten und Poeten. Die Grammatik einer Mentalität im tolosanischen Hochmittelalter
}

\author{
Stéphane Péquignot
}

1 Issu d'une thèse soutenue en 1998 à l'université de Bâle, l'ouvrage a pour objectif la reconstitution de la «mentalité » des hommes de Toulouse au XIIe et au début du XIIIe s. à partir de l'étude d'un groupe de 18 familles de patriciens ou aristocrates urbains. Le recours à des concepts d'anthropologie culturelle, la discussion de l'historiographie régionaliste, les influences conjuguées du linguistic turn et de l'histoire des mentalités " à la française » se traduisent par une approche de la Mentalität occitane conçue comme un "système symbolique de signes ». Se fondant sur une documentation variée (cartulaire de la ville de Toulouse, chants des troubadours, sources narratives de la guerre des Albigeois), mais souvent parcellaire, ainsi que sur les travaux de John Hine Mundy, J.R. analyse d'abord les caractéristiques sociales de l'habitus aristocratique des patriciens de Toulouse. L'absence de hiérarchisation nette au sein de la parenté arborescente de la fratrisca/frairesca, la faible projection généalogique des familles et la pénétration quasiment inexistante des relations féodo-vassaliques constituent autant d'arguments a silentio qui témoignent d'un contraste saisissant avec le modèle mis en lumière par Georges Duby pour la France du Nord-Ouest. Les probi homines de Toulouse demeurent des pairs, des égaux qui se distinguent des autres hommes essentiellement par la valeur intangible de leur parole. Leurs pratiques culturelles présentent des spécificités linguistiques remarquables, car la diglossie latin/occitan est ancienne dans la région (depuis 1100 environ) et l'occitan, à la différence des autres langues vernaculaires, est employé pour les mêmes genres littéraires que le latin. La place attribuée à la femme (la domna) et l'organisation acéphale des cours diffèrent aussi très fortement de la situation au nord de la Loire. Les mots et leurs usages jouent dans cette perspective un rôle fondamental ; l'auteur procède donc à une étude détaillée du discours de la courtoisie occitane (cortesia), qui est entendue de manière extensive comme une grammaire, avec une syntaxe, une sémantique et des modalités d'usages singulières. Au fondement de cette " grammaire de la mentalité » courtoise 
qui s'approprie de manière sélective des influences latines, arabes et barbares, on trouve la fin'amor, considérée par J.R. comme une véritable langue, un " système de signes " qui s'articule autour du triptyque " homme-femme-amor ». De ce modèle théorique complexe, qui peut sembler par moments excessivement rigide, une idée ressort avec force : la cortesia n'est pas la cortoisie du nord. Les deux dernières parties du livre sont ensuite consacrées aux différents usages de la langue de la cortesia par les Toulousains au début du XIIIe s., une langue modifiée par l'introduction de nouveaux termes (senhor, cavalier) et qui doit faire face à un choc culturel considérable lors de la croisade albigeoise. Il s'agit notamment de rendre dicible et légitime la guerre face aux croisés. C'est la tâche assumée par le continuateur anonyme de la Cançon de la Crosada de Guillem de Tudela, qui justifie la lutte par la défense d'un modèle social fondé sur l'eretat et le paratge et réévalue ainsi la place assignée à ces deux concepts dans la cortesia. Réussite littéraire incontestable, démonstration de la capacité d'adaptation de la cortesia, l'épopée-plaidoyer du continuateur de la Cançon de la crosada résonne aussi comme le chant du cygne d'une culture courtoise occitane définitivement marginalisée à partir du milieu des années 1220 .

2 Stéphane PÉQUIGNOT 